Selcuk Journal of Agriculture and Food Sciences

http://sjafs.selcuk.edu.tr/sjafs/index

Research Article
SJAFS

(2020) 34 (1), 91-98

e-ISSN: 2458-8377

DOI:10.15316/SJAFS.2020.200

\title{
Comparison of Resampling and Bayesian Approaches in Variance Component Estimation of a Hierarchical Univariate Mixed Effect Model
}

\author{
Doğan NARINÇ̧, ${ }^{1, *}$, Nihan ÖKSÜZ NARINÇ̧² \\ ${ }^{1}$ Akdeniz University, Faculty of Agriculture, Department of Animal Science, Antalya, Turkey \\ ${ }^{2}$ Akdeniz University, Faculty of Applied Sciences, Department of Banking and Finance, Antalya, Turkey
}

\begin{tabular}{l}
\hline ARTICLE INFO \\
\hline Article history: \\
Received date: 31.01 .2020 \\
Accepted date: 22.03 .2020 \\
\hline Edited by: \\
İbrahim AYTEKİN; Selçuk University, \\
Turkey \\
Reviewed by: \\
Ali AYGÜN; Selçuk University, Turkey \\
Eser Kemal GÜRCAN; Tekirdağ Namık \\
Kemal University, Turkey \\
Hande KÜÇÜKÖNDER; Bartın Univer- \\
sity, Turkey \\
\hline Keywords: \\
Bayesian \\
Gibbs Sampling \\
VCE \\
REML \\
Bootstrap
\end{tabular}

\section{Introduction}

Two different approaches are effective in statistics; these are the classical (frequentist) approach and the probabilistic (Bayesian) approach (Browne \& Draper 2006; Wagenmakers et al 2008). The classical approach is based on the deductive method and evaluates the parameter as an unknown constant and is based on the frequency-based estimation of probability. The Bayesian approach is a technique based on the induction method and evaluates the parameter as a chance variable with a probability distribution. The Bayesian approach reveals the probability of an event by combining it with experience (prior) with the information obtained from the trial.Bayesian theorem gives the relationship between conditional probabilities and marginal probabilities in a probability distribution for a random variable.Bayes Theorem was presented in 1763 with the article "An Essay towards Solving a Problem in the Doctrine of Chances" written by Thomas Bayes, a British priest and mathematician. Although centuries have passed since its publication, the theory has found

\footnotetext{
* Corresponding author email: dnarinc@akdeniz.edu.tr
}

its chance to regain popularity after the mid- $20^{\text {th }}$ century.The classical approach accepts the frequency definition of probability. According to this definition, the probability of an event is the frequency of many repeated attempts of that event. In the Bayesian approach, the parameter is considered as a random variable with a probability distribution. Accordingly, a prior probability distribution is determined for the estimator of the parameter. Thus, past experiences are included in the analysis. The final probability distribution (posterior) of the parameter is obtained by combining with the actual data. In the classical approach, the parameter is seen as an unknown constant. Parameter estimation is calculated only based on the data available. The Bayesian approach, the point estimate of the parameter is usually the mean value of the final distribution (posterior mean), when the value calculated using appropriate methods is defined as the best estimate (point estimate) in the frequentist approach.

Resampling is a way to reuse observations of existing sample data to create new hypothetical samples that represent the actual population. It is generally used when the population distribution is unknown and in cases where effective sample size is difficult to reach. 
Some resampling methods (Bootstrap, Jackknife, etc.) have been used frequently in recent years for making predictions of unknown parameters of a population, establishing confidence intervals and testing hypotheses. Bootstrapping is the most popular resampling method today and uses sampling with replacement to estimate the sampling distribution of the estimator (Delpish 2009). The difference between resampling methods and Bayesian approach is based on repetitive sampling in the same sample in resampling technique. However, in the Monte Carlo simulation, the data is created purely on a theoretical basis through an algorithm. The use of resampling methods for parameter estimation as an alternative to the classical approach is similar to the Bayesian approach when there is no prior knowledge of the parameters of the population being studied, but only one sample is observed. This parameter estimation method, which basically contains the frequentist algorithm but looks like a Bayesian technique, can be called a semi-frequentist approach.

Statistical models are three types as a fixed effect, random effect, mixed effect. While the hypothesis tests that compare the classes of the variables are performed for fixed effect models, it is desired to know the rates of the components that create total variation in random and mixed effect models (Searle et al 2006; Rash \& Masata 2006). One of the goals of applied statistical methods is to estimate variance components. Researchers want to determine the components of the variance observed in the data obtained at the end of the experiment and how much of total variance is caused by which reasons (Dağ et al 2003; Gökmen et al 2008; Altay et al 2019). It is desirable that the rate of error variance is small in the total variance and that the part of the total variance that can be explained by mixed effects is high. Researchers want to make some generalizations or conclusions based on their results (Zülkadir \& Aytekin 2009; Aytekin et al 2019). Many studies are carried out to estimate the variance components in fields such as agriculture, genetics, medicine, economics, astronomy and space sciences, and physics, where the applied statistics field is used extensively (Zülkadir et al 2008).

In a mixed linear model $(\mathrm{y}=\mathrm{Xb}+\mathrm{Zu}+\mathrm{e})$, if the variance-covariance matrix $\mathrm{V}$ is unknown, then the variance $D$ of $V=Z D Z$ ' $R$ and the error variance $R$ must be estimated. The estimation of these two matrices forming $\mathrm{V}$ is called the estimation of the variance components. Various methods have been developed to make these predictions. The first studies for the estimation of variance elements were performed by R. A Fisher (Robinson 1987, Searle et al 2006). The basic principle of this method, known as the ANOVA (Analysis of Variance) method, consists of solving the linear equation system obtained after equalizing the mean of squares to their expected values (Theobald et al 1997). However, studies at that time were limited only to balanced data or single factor unbalanced data (Robinson, 1987). Henderson developed the methods named after him (Henderson Type 1, 2, 3) (Searle et al 2006).
Since ANOVA and Henderson methods are designed for balanced data, negative variance elements can also be estimated in the data obtained from the sample. In contrast, ML (Maximum Likelihood-maximum likelihood) and REML (Restricted Maximum Likelihoodrestricted maximum likelihood) methods have been developed (Hartley \& Rao 1967; Patterson \& Thompson 1971). These two methods based on likelihood are asymptotic normality, consistency and being within the parameter definition range (Firat 2000). ML and REML methods are the most used applications because the variance elements do not give negative estimates. Different estimators are also used in the Bayesian estimation of variance elements. According to the Bayesian approach, the expected values are obtained by selecting samples from the required distribution with Monte Carlo integration and using the sample averages. There are estimation methods such as Metropolis Hastings algorithm and Gibbs sampling to obtain Markov chains according to specific properties. Gibbs sampling, which is a powerful iterative method for estimating posterior distributions, is a very popular method for predicting variance components. Gibbs sampling approaches the joint conditional density function of all parameters in the model by sampling from all full conditional density functions (Frrat, 1996).

In a study by Harville (2004), was reported to the Gibbs sampler can be used to estimate iterates of a first-order REML algorithm. In the study, it was claimed that the use of the REML estimator is good for large data sets and the use of the Gibbs sampler is a good alternative to traditional numerical methods.In a study by Browne \& Draper (2006), simulation studies whose design is realistic for education and medical research (and other research areas) were used to compare Bayesian and probability-based methods for the estimation of variance components.In the study performed by Delpish (2009), the variance components were estimated in the sample distributed $\chi^{2}$ using the minimum norm quadratic estimation estimator with the Bootstrap technique and using REML estimator for a two-level hierarchical linear model.According to the results of the study, although the estimations of fixed effects are correct both through Bootstrap MINQUE and REML, the efficiency of the estimates was determined to be affected by the distribution of errors for both procedures, especially for variance-covariance component estimates.It was concluded that the Bootstrap via MINQUE appears to be an attractive alternative to estimation in cases where normality is not guaranteed.The purpose of the study is to investigate the relative performance of two estimation procedures, a semi-frequentist estimation technique (via a Bootstrapped the restricted maximum likelihood: BootREML) and Bayesian method (via a Gibbs sampler), for estimation of variance components of a two level hierarchical linear mixed model. 


\section{Materials and Methods}

In the study, one variable named $\mathrm{X}$ for the structure of two level nested designs was obtained using simulations in an $\mathrm{R}$ package which showed Gaussian distribution. The variable X contains 10000 data, with an average of 0 and variances of 100 which are shown in the frequency histogram plots in Figure 1.

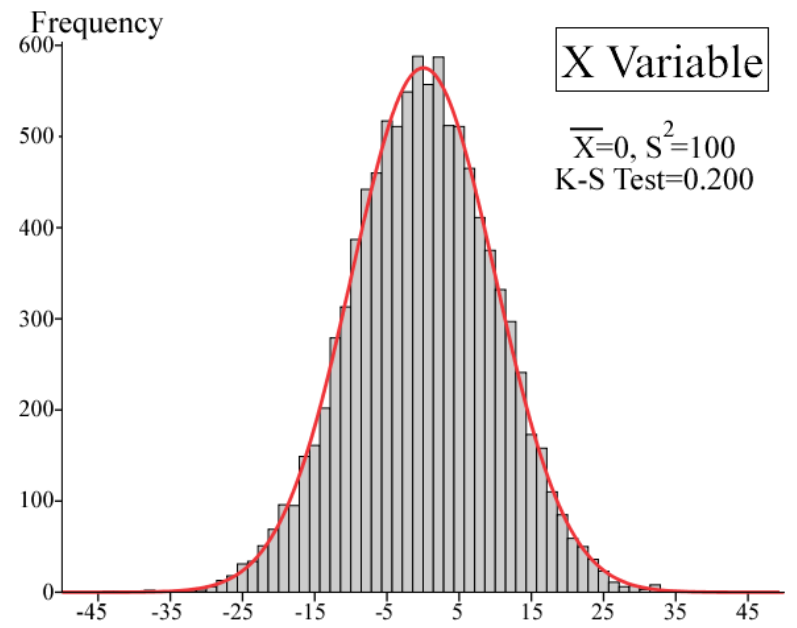

Figure 1

Frequency histogram with Gaussian distribution curveof $\mathrm{X}$ variable

According to the two levels of nested design (a and $\mathrm{b}$ (a)), which constitute the two factors that this X vari- able is associated with, 5 different scenarios have been constructed using the classical ML estimator for the proportions of the variance components. The five different scenarios mentioned are presented in Table 1.

Table 1

Variance components scenarios of simulated data

\begin{tabular}{lccc}
\hline Scenario & $\sigma_{a}^{2}$ & $\sigma_{b(a)}^{2}$ & $\sigma_{e}^{2}$ \\
\hline 1 & 2 & 3 & 95 \\
2 & 20 & 5 & 75 \\
3 & 45 & 5 & 50 \\
4 & 70 & 5 & 25 \\
5 & 90 & 5 & 5 \\
\hline
\end{tabular}

In the analysis of the data, the univariate mixed linear model shown as $\mathrm{y}=\mathrm{X} \beta+\mathrm{Zu}+\mathrm{e}$ was used for the $\mathrm{N}$ dimensional y observation vector. In the model, $\mathrm{X}, \mathrm{g}$ dimensional fixed effects vector; mat, $\mathrm{Nxg}$ dimensional fixed effects pattern matrix; $Z$, s dimensional chancerelated effects vector; $u$ is the pattern matrix of Nxs dimensional chance-related effects and $\mathrm{e}$ is the vector of N-size chance-related errors.

The Gibbs sampler was used in Bayesian analysis of variance component estimation. the prior distribution in Gibbs sampling; the uniform prior $(f(\beta)=$ sabit) for fixed effect parameter and it is assumed that random effects show normal distribution $\left(\mathrm{u} \mid \sigma_{\mathrm{a}}^{2} \sim \mathrm{N}\left(0, \mathrm{I}, \sigma_{\mathrm{a}}^{2}\right)\right)$. It is assumed that the conjugate density functions of the prior distributions of the variance components $\sigma_{a}^{2}, \sigma_{\mathrm{b}(\mathrm{a})}^{2}$ and $\sigma_{e}^{2}$ as follows (1);

$$
\begin{aligned}
& f\left(\sigma_{a}^{2}, \sigma_{b(a)}^{2} \sigma_{e}^{2} \mid v_{a}, s_{a}^{2}, v_{b}(a), s_{b}^{2}(a), v_{e}, s_{e}^{2}\right)
\end{aligned}
$$

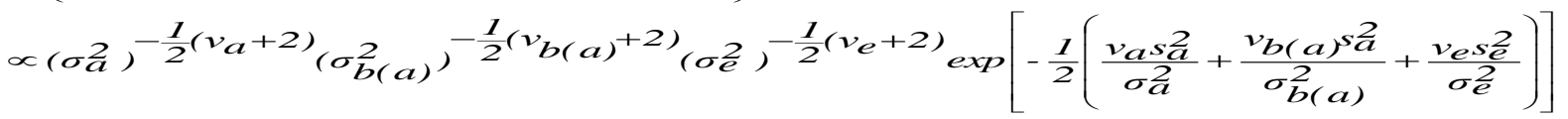

It is understood from this function (1), that $\sigma_{a}^{2}, \sigma_{\mathrm{b}(\mathrm{a})}^{2}$ and $\sigma_{e}^{2}$ follow independent and inverse chi-square distributions. Thus, $\sigma_{a}^{2}, \sigma_{\mathrm{b}(\mathrm{a})}^{2}$ and $\sigma_{e}^{2}$ are interpreted as the prior expected values of $\sigma_{a}^{2}, \sigma_{\mathrm{b}(\mathrm{a})}^{2}$ and $\sigma_{e}^{2}$, respectively, whereas the precision parameters are equivalent to the degrees of freedom of $v_{a}^{2}, v_{\mathrm{b}(\mathrm{a})}^{2}$ and $v_{e}^{2}$ (Firat, 1996a). Gibbs sampling, which is a powerful iterative algorithm to study posterior distributions in complex Bayesian models, generates sample values for the common posterior density distribution of all parameters in the model by sampling from all full conditional distributions, respectively. For this purpose, all variables $\left(\beta, \mathrm{u}, \sigma_{a}^{2}, \sigma_{\mathrm{b}(\mathrm{a})}^{2}\right.$ and $\left.\sigma_{e}^{2}\right)$ are given a random initial value and a Markov chain is created when a cycle is completed by updating the previous one for each variable (Firat, 1996b).

In this study, this process was repeated 55000 times for variable $\mathrm{X}$ and repeated each scenario, and marginal posterior distributions were obtained from a single long chain per scenarios. In the meantime, the first 5000 burn-in parts of Gibbs chains were removed, and the thinning interval value was accepted as 200 for the remaining chain for dilution according to the effective independent sample numbers calculated by using time- interval auto-covariances. Gibbs sampling was performed using the R program's MCMCglmm library (Hadfield, 2010). In this study, simulation data was used and no fictional data was simulated, and parameters were selected appropriately for convenience in calculations and estimates. In the estimates of the variance components of each scenario obtained from the mentioned data, the methodology of the REML estimation is described by Firat (2000). As explained by Efron \& Tibshirani (1993), Bootstrap technique was applied for variable $\mathrm{X}$ and each scenario. For this purpose, in the data set consisting of 10000 observations, the observations were changed and bootstrap sample datasets were generated with a choice of $1 / 10000$ probability. In the study, 250 different samples were obtained with the Bootstrap method for each scenario and the SAS macros presented below were written to perform this operation. The SAS program macro also includes the varcomp procedure and REML method used for variance component estimation. 
Table 2

A SAS macro codes for Bootstrapped REML variance component estimator

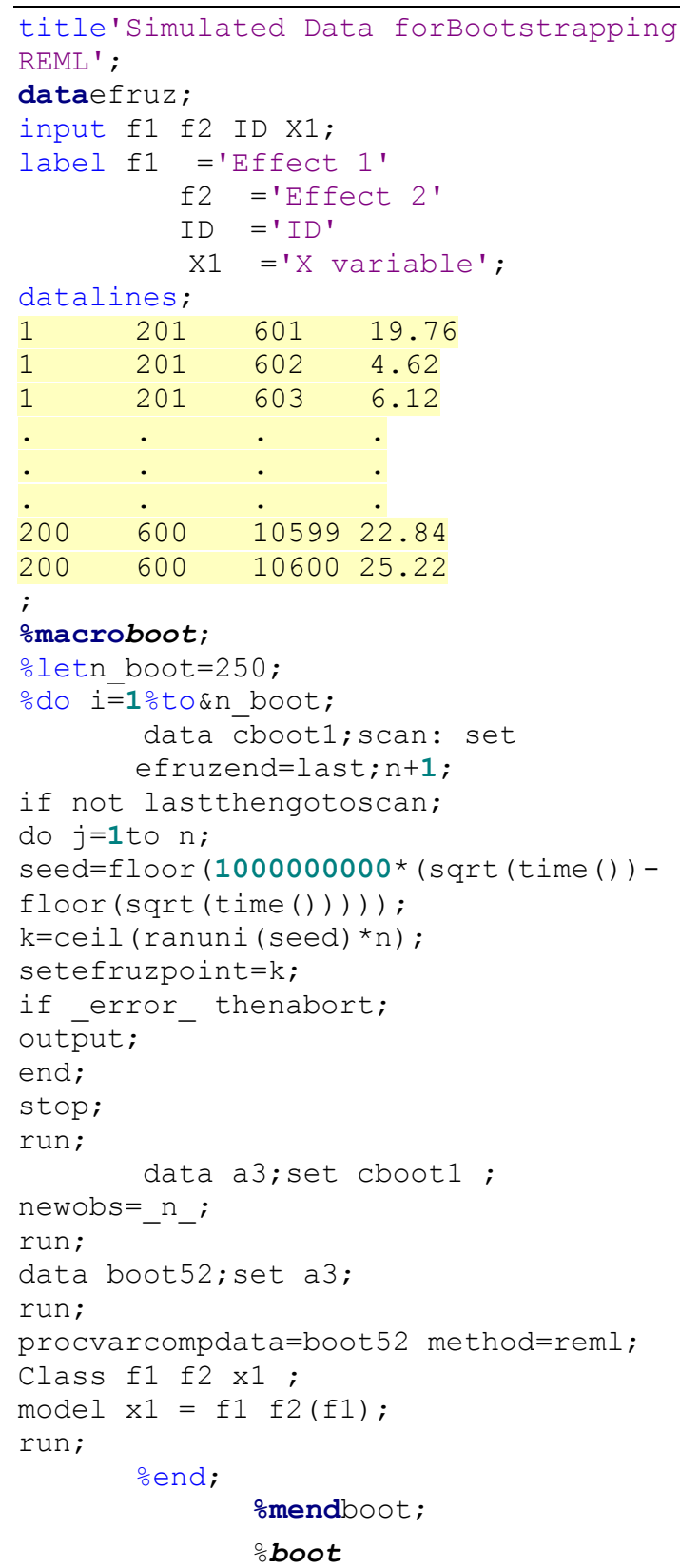

After all estimations the definitions of autocorrelation and bias were performed on the posterior distributions and bootstrapped parameter distributions generated for the variance components of each of the scenarios. Data simulation, Gibbs sampling, Durbin-Watson statistic and, all other statistical analyses were performed using different packages of the $\mathrm{R}$ program, Bootstrap and REML estimations of variance components were performed using different procedures of the SAS program.

\section{Results and Discussion}

The descriptive statistics of posterior distributions of parameters and the distributions of Bootstrap samples are presented in Table 3 and Table 4, respectively.
Table 3

The descriptive statistics of posterior distributions of variance component estimates (VC) from Gibbs sampler

\begin{tabular}{|c|c|c|c|c|c|c|}
\hline \multirow[t]{2}{*}{ Scenario } & \multirow[t]{2}{*}{ VC } & \multirow[t]{2}{*}{ Mean } & \multirow[t]{2}{*}{ SE } & \multirow[t]{2}{*}{ Median } & \multicolumn{2}{|c|}{$\begin{array}{c}\text { Confi- } \\
\text { denceIntervals }\end{array}$} \\
\hline & & & & & $2.5 \%$ & $97.5 \%$ \\
\hline \multirow{3}{*}{ S1 } & $\sigma_{a}^{2}$ & 2.05 & 0.01 & 2.05 & 2.02 & 2.08 \\
\hline & $\sigma_{\mathrm{b}(\mathrm{a})}^{2}$ & 3.04 & 0.01 & 3.04 & 3.02 & 3.07 \\
\hline & $\sigma_{e}^{2}$ & 93.95 & 0.06 & 93.91 & 93.82 & 94.07 \\
\hline \multirow{3}{*}{ S2 } & $\sigma_{a}^{2}$ & 21.09 & 0.11 & 21.06 & 20.84 & 21.34 \\
\hline & $\sigma_{\mathrm{b}(\mathrm{a})}^{2}$ & 4.60 & 0.02 & 4.57 & 4.55 & 4.64 \\
\hline & $\sigma_{e}^{2}$ & 73.82 & 0.05 & 73.77 & 73.71 & 73.93 \\
\hline \multirow{3}{*}{ S3 } & $\sigma_{a}^{2}$ & 45.35 & 0.19 & 45.07 & 44.91 & 45.78 \\
\hline & $\sigma_{\mathrm{b}(\mathrm{a})}^{2}$ & 4.66 & 0.02 & 4.68 & 4.62 & 4.71 \\
\hline & $\sigma_{e}^{2}$ & 49.34 & 0.03 & 49.34 & 49.27 & 49.42 \\
\hline \multirow{3}{*}{ S4 } & $\sigma_{a}^{2}$ & 70.82 & 0.31 & 69.98 & 70.12 & 71.52 \\
\hline & $\sigma_{\mathrm{b}(\mathrm{a})}^{2}$ & 4.15 & 0.01 & 4.15 & 4.12 & 4.19 \\
\hline & $\sigma_{e}^{2}$ & 24.79 & 0.02 & 24.79 & 24.76 & 24.83 \\
\hline \multirow{3}{*}{ S5 } & $\sigma_{a}^{2}$ & 91.53 & 0.42 & 90.82 & 90.57 & 92.48 \\
\hline & $\sigma_{\mathrm{b}(\mathrm{a})}^{2}$ & 3.88 & 0.01 & 3.86 & 3.85 & 3.92 \\
\hline & $\sigma_{e}^{2}$ & 4.60 & 0.00 & 4.60 & 4.59 & 4.61 \\
\hline
\end{tabular}

The mean and median values of the distributions obtained by estimating the variance components with both Gibbs sampling and the Bootstrap-REML estimator show that the posterior distributions are Gaussian.

Table 4

The descriptive statistics of variance component estimates (VCE) distributions of Bootstrap-REML estimation

\begin{tabular}{lcrlrrr}
\hline \multirow{2}{*}{ Scenario } & & & & & \multicolumn{2}{c}{ Confi- } \\
& $\mathrm{VC}$ & Mean & SE & Median & \multicolumn{2}{c}{ denceIntervals } \\
& & & & & $2.5 \%$ & $97.5 \%$ \\
\hline \multirow{3}{*}{ S1 } & $\sigma_{a}^{2}$ & 7.05 & 0.05 & 7.08 & 6.94 & 7.16 \\
& $\sigma_{\mathrm{b}(\mathrm{a})}^{2}$ & 2.12 & 0.04 & 2.12 & 2.04 & 2.20 \\
& $\sigma_{e}^{2}$ & 88.76 & 0.09 & 88.75 & 88.56 & 88.95 \\
\cline { 2 - 7 } S2 & $\sigma_{a}^{2}$ & 23.24 & 0.04 & 23.22 & 23.16 & 23.32 \\
& $\sigma_{\mathrm{b}(\mathrm{a})}^{2}$ & 5.22 & 0.04 & 5.17 & 5.12 & 5.31 \\
& $\sigma_{e}^{2}$ & 69.88 & 0.08 & 69.82 & 69.70 & 70.06 \\
\cline { 2 - 7 } S3 & $\sigma_{a}^{2}$ & 46.40 & 0.03 & 46.45 & 46.34 & 46.47 \\
& $\sigma_{\mathrm{b}(\mathrm{a})}^{2}$ & 5.33 & 0.03 & 5.35 & 5.26 & 5.41 \\
& $\sigma_{e}^{2}$ & 46.65 & 0.07 & 46.60 & 46.50 & 46.80 \\
\cline { 2 - 7 } S4 & $\sigma_{a}^{2}$ & 72.40 & 0.02 & 72.41 & 72.34 & 72.45 \\
& $\sigma_{\mathrm{b}(\mathrm{a})}^{2}$ & 2.46 & 0.02 & 2.43 & 2.41 & 2.52 \\
& $\sigma_{e}^{2}$ & 23.53 & 0.05 & 23.45 & 23.42 & 23.65 \\
\cline { 2 - 7 } S5 & $\sigma_{a}^{2}$ & 92.93 & 0.01 & 92.93 & 92.90 & 92.96 \\
& $\sigma_{\mathrm{b}(\mathrm{a})}^{2}$ & 1.64 & 0.01 & 1.62 & 1.61 & 1.68 \\
& $\sigma_{e}^{2}$ & 4.03 & 0.02 & 4.02 & 3.99 & 4.08 \\
\hline
\end{tabular}


By the scenarios and components, the amount of bias $(\%)$, change $(\%)$ and Durbin Watson statistics for distributions estimated using Gibbs Sampling and Bootstrap-REML estimatorwere presented in Table 5 and Table 6, respectively.

Significant differences were observed between Bootstrap-REML and Gibss sampling methods in terms of biases in parameter estimates and changes in total variance. When Gibbs sampling results are examined, biased results are lower in scenarios where the error variance share is large, on the contrary, bias in estimates increased as the rate of error variance decreased. In the Gibbs sampling method, the bias of the b(a) factor of nested designed model was found to be higher than the bias results of other variance components.In terms of biased estimates in the estimation of variance elements, the results of the Bootstrap-REML method were found worse than the Gibbs sampling.

Especially in scenario 1 where the error variance is highest, the biases realized with the Bootstrap-REML method for $\sigma_{a}^{2}, \sigma_{\mathrm{b}(\mathrm{a})}^{2}$ and $\sigma_{e}^{2}$ are $257.37 \%, 29.27 \%$ and $6.57 \%$, respectively. In terms of bias in estimates, the results obtained for scenario 4 and scenario 5 were found to be quite high in the analyses made with the Bootstrap-REML method. The lowest biased variance component estimation results were found for Gibbs sampling for scenario 1and for Bootstrap-REML for scenario 3.

Table 5

The amount ofbias (\%), change (\%) and Durbin Watson statistics for distributions estimated using Gibbs Samplingby scenarios and components

\begin{tabular}{ccccc}
\hline & $\begin{array}{c}\text { Variance } \\
\text { Component }\end{array}$ & $\begin{array}{c}\text { Bias } \\
\%\end{array}$ & $\begin{array}{c}\text { Change } \\
\%\end{array}$ & $\begin{array}{c}\text { Durbin } \\
\text { Watson }\end{array}$ \\
\hline \multirow{3}{*}{$\mathrm{S} 1$} & $\sigma_{a}^{2}$ & 2.49 & & 1.90 \\
& $\sigma_{\mathrm{b}(\mathrm{a})}^{2}$ & 1.46 & 0.96 & 2.05 \\
& $\sigma_{e}^{2}$ & 1.11 & & 1.95 \\
\cline { 2 - 5 } $\mathrm{S} 2$ & $\sigma_{a}^{2}$ & 5.46 & & 1.87 \\
& $\sigma_{\mathrm{b}(\mathrm{a})}^{2}$ & 8.10 & 0.49 & 1.99 \\
& $\sigma_{e}^{2}$ & 1.57 & & 1.99 \\
\cline { 2 - 5 } $\mathrm{S} 3$ & $\sigma_{a}^{2}$ & 0.77 & & 2.10 \\
& $\sigma_{\mathrm{b}(\mathrm{a})}^{2}$ & 6.70 & 0.65 & 1.96 \\
& $\sigma_{e}^{2}$ & 1.31 & & 2.01 \\
\cline { 2 - 5 } $\mathrm{S} 4$ & $\sigma_{a}^{2}$ & 1.18 & & 2.03 \\
& $\sigma_{\mathrm{b}(\mathrm{a})}^{2}$ & 16.93 & 0.23 & 2.04 \\
& $\sigma_{e}^{2}$ & 0.83 & & 2.12 \\
\cline { 2 - 5 } $\mathrm{S} 5$ & $\sigma_{a}^{2}$ & 1.70 & & 1.92 \\
& $\sigma_{\mathrm{b}(\mathrm{a})}^{2}$ & 22.31 & -0.01 & 2.07 \\
& $\sigma_{e}^{2}$ & 7.98 & & 1.98 \\
\hline \multirow{3}{*}{} & & & &
\end{tabular}

Table 6

The amount of bias (\%), change (\%) and Durbin Watson statistics for distributions estimated using Bootstrap-REMLby scenarios and components

\begin{tabular}{ccccc}
\hline & $\begin{array}{c}\text { Variance } \\
\text { Component }\end{array}$ & $\begin{array}{c}\text { Bias } \\
\%\end{array}$ & $\begin{array}{c}\text { Change } \\
\%\end{array}$ & $\begin{array}{c}\text { Durbin } \\
\text { Watson }\end{array}$ \\
\hline \multirow{3}{*}{$\mathrm{S} 1$} & $\sigma_{a}^{2}$ & 252.37 & & 0.06 \\
& $\sigma_{\mathrm{b}(\mathrm{a})}^{2}$ & 29.27 & 2.07 & 0.02 \\
& $\sigma_{e}^{2}$ & 6.57 & & 0.05 \\
\cline { 2 - 5 } $\mathrm{S} 2$ & $\sigma_{a}^{2}$ & 16.19 & & 2.04 \\
& $\sigma_{\mathrm{b}(\mathrm{a})}^{2}$ & 4.30 & 1.66 & 2.06 \\
& $\sigma_{e}^{2}$ & 6.82 & & 1.92 \\
\cline { 2 - 5 } $\mathrm{S} 3$ & $\sigma_{a}^{2}$ & 3.12 & & 2.12 \\
& $\sigma_{\mathrm{b}(\mathrm{a})}^{2}$ & 6.65 & 1.61 & 2.27 \\
& $\sigma_{e}^{2}$ & 6.70 & & 2.28 \\
\cline { 2 - 5 } $\mathrm{S} 4$ & $\sigma_{a}^{2}$ & 3.43 & & 1.94 \\
& $\sigma_{\mathrm{b}(\mathrm{a})}^{2}$ & 50.75 & 1.61 & 1.91 \\
& $\sigma_{e}^{2}$ & 5.87 & & 2.19 \\
\cline { 2 - 5 } $\mathrm{S} 5$ & $\sigma_{a}^{2}$ & 3.26 & & 2.20 \\
& $\sigma_{\mathrm{b}(\mathrm{a})}^{2}$ & 67.13 & 1.39 & 1.76 \\
& $\sigma_{e}^{2}$ & 19.35 & & 2.12 \\
\hline
\end{tabular}

The distributions of parametersobtained from Gibbs sampling and Bootstrap-REML estimator were presented in Figure 2 and Figure 3, respectively. 
Narinç and Narinç / Selcuk J Agr Food Sci, (2020) 34 (1), 91-98
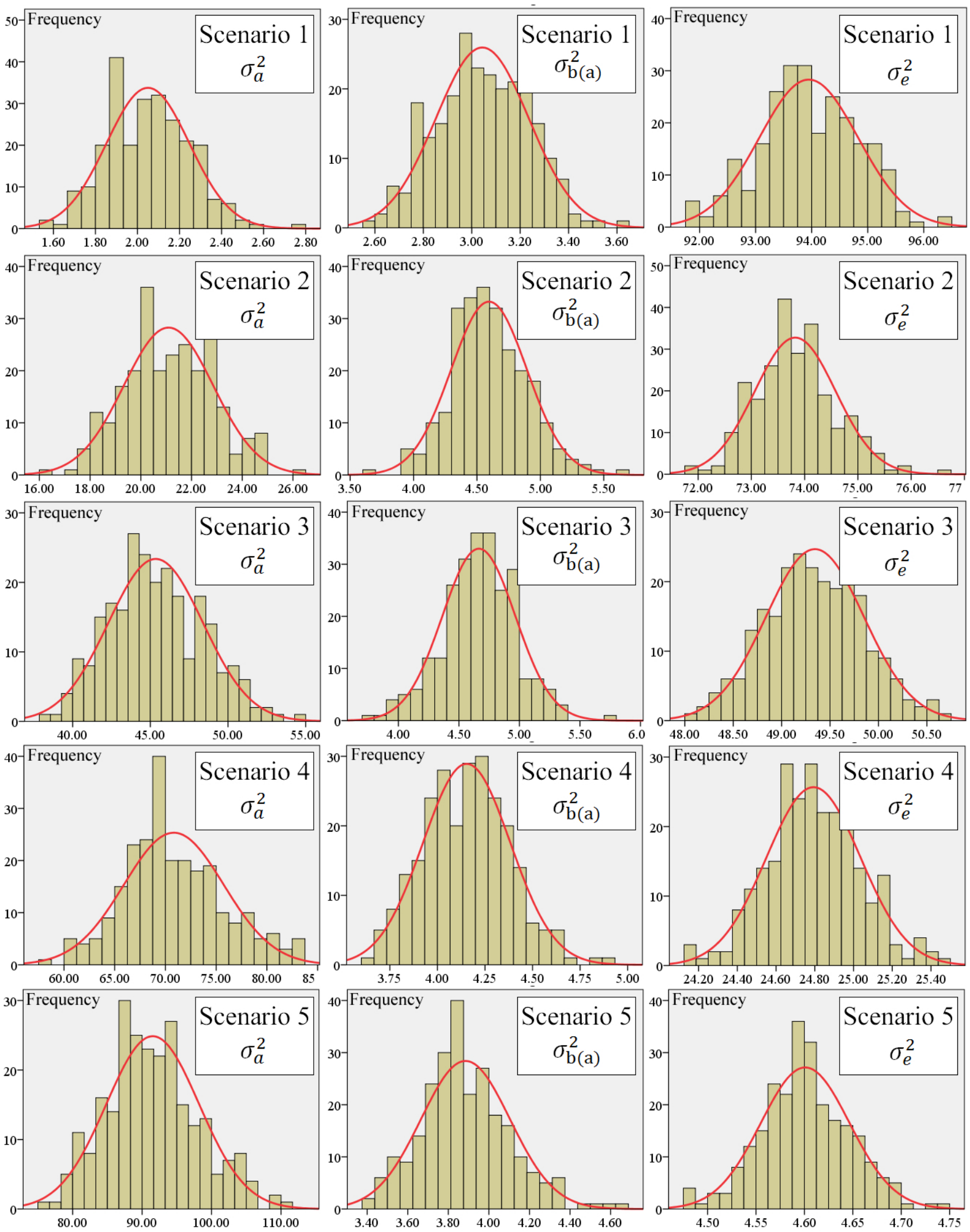

$\begin{array}{lllllll}24.20 & 24.40 & 24.60 & 24.80 & 25.00 & 25.20 & 25.40\end{array}$

Figure 2

The frequency distributions for variance components estimated using the Gibbs sampling for each scenario and for each parameter 

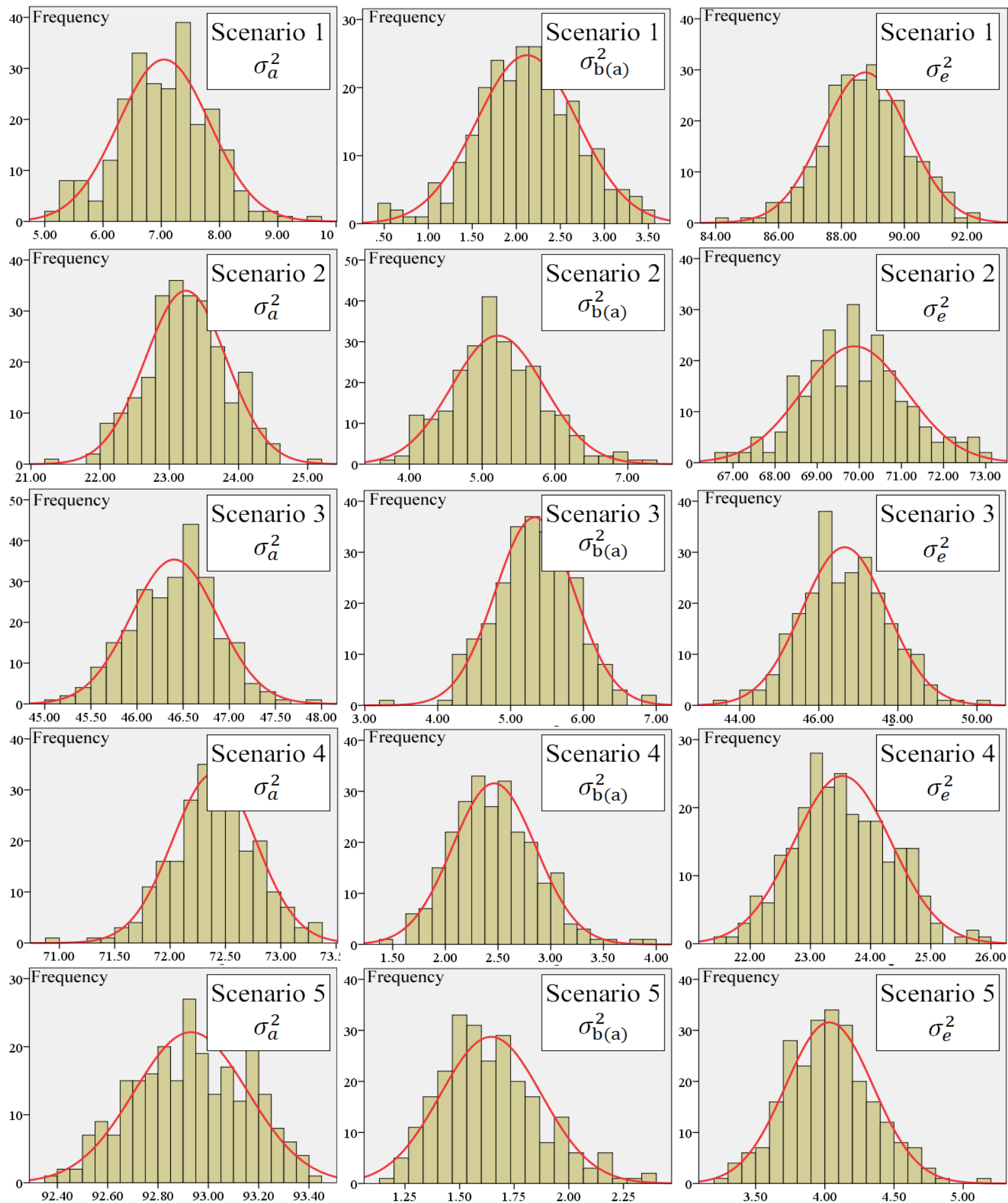

Figure 3

The frequency distributions for variance components estimated using the Bootstrap-REML sampler for each scenario and for each parameter

Similar results were obtained for both estimation methods in terms of changes in the total variation, which is another criterion in which Gibbs sampling and Bootstrap-REML method can be compared in the estimation of variance components. Similar results were obtained for both estimation methods in terms of changes in the amount of total variance, which is another criterion in which Gibbs sampling and Bootstrap-
REML method can be compared in the estimation of variance components. While the decrease in the total variance estimated by both methods occurs, the amount of this decrease is less of the Gibbs sampling method than the Bootstrap-REML method. In point of autocorrelation, in all the scenarios tested in both estimation methods, only the Bootstrap-REML method deter- 
mined a significant positive relationship in the distribution of all three parameters in scenario 1 .

In a study conducted by Delpish (2009), variance elements were estimated by using REML and Bootstrap-Minque estimators, and bias amounts were quite small in accordance with this study. Different researchers (Swallow \& Monahan 1984; Raudenbush \& Bryk 1986; Delpish 2009; Narinç et al 2011) have performed similar comparison using different variance component estimator for balanced-unbalanced data or nonGaussian distributed data. In this study, 5 different scenarios were emphasized by keeping the sample size (10000) constant. Based on the results of Delpish's work, it is possible to say that the Bootstrap-MINQUE is an attractive alternative to predictions when normality is not guaranteed. Maas \& Hox (2005) proposed a similar proposal, according to which they said that Bootstrap was a different approach that caught the attention of analysts if the assumption of normality was violated. However, according to the results of this study, it is not possible to say that using the BootstrapREML technique under Gaussian distribution is a good alternative. Perhaps different results may be obtained from another study using unbalanced data, nonnormally distributed data and high sample sizes. Therefore, it is recommended that the similar study be carried out for unbalanced data, non-normally distributed data and high sample sizes.

\section{References}

Altay Y, Kılıç B, Aytekin İ, Keskin İ (2019). Determination of factors affecting mastitis in Holstein Friesian and Brown Swiss by using logistic regression analysis. Selcuk Journal of Agriculture and Food Sciences, 33(3), 194197.

Aytekin İ, Doğan Ş, Odacı Ö, Gökcan G (2019). Estimation of variance components for birth and weaning weights in holstein-friesian calves by using WOMBAT software. Selcuk Journal of Agriculture and Food Sciences, 33(2), 88-93.

Browne WJ, Draper D (2006). A comparison of Bayesian and likelihood-based methods for fitting multilevel models. Bayesian analysis, 1(3), 473-514.

Dağ B, Keskin İ, Zülkadir U, Boztepe S (2003). Çumra Ziraat Meslek Lisesinde (Konya) yetiştirilen Esmer ineklerin süt verim özellikleri ve bu özelliklere ait tekrarlanma dereceleri. Selçuk Üniversitesi Ziraat Fakültesi Dergisi, 17(31), 13-17.

Delpish A (2009). Comparison of Restricted Maximum Likelihood and Bootstrap via Minimum Norm Quadratic Unbiased Estimators for Hierarchical Linear Models under X $1 / 2$ Assumptions. Journal of Statistical Research, 43(1), 69.

Efron B, Tibshirani R (1993) An Introduction to the Bootstrap. New York: Chapman and Hall.

Firat MZ (1996a). Some Aspects of the Bayesian Approach to Statistical Modelling in Animal Breeding. Turkish Journal Of Veterinary And Animal Sciences, 20(5), 353358.
Firat MZ (1996b). Bayesian methods in animal breeding with different prior specification using gibbs sampling. Turkish Journal Of Veterinary And Animal Sciences, 20(5), 359-365.

Firat MZ (2000). Comparative investigation of variance analysis, maximum 11 kellhood andrestricted maximum 11 kellhood for the estimation of variance components in balanced two-stage random nested designs. AnadoluÜniversitesiBilimveTeknolojiDergisi, 1, 105-113.

Gökmen M, Sarıyel V, Keskin İ, Dağ B (2008). Konya Merinosu koyunlarda bazı çevre faktörlerinin gebelik süresine etkileri. Selcuk Journal of Agriculture and Food Sciences, 22(44), 26-29.

Hadfield JD (2010). MCMC methods for multi-response generalized linear mixed models: the MCMC glmm R package. Journal of Statistical Software, 33(2), 1-22.

Hartley HO, Rao JN (1967). Maximum-likelihood estimation for the mixed analysis of variance model. Biometrika, 54(1-2), 93-108.

Maas, CJM, Hox, JJ (2005). Sufficient Sample sizes for Multilevel Modeling Methodology, 1(3), 85-91.

Narinç D, Karaman E, Firat MZ, Aksoy T (2011). Estimation of multiple-trait genetic parameters and BLUP using different estimation methods for some egg traits in Japanese quails. Kafkas Üniversitesi Veteriner Fakültesi Dergisi, 17(1), 117-123.

Patterson HD, Thompson R (1971). Recovery of inter-block information when block sizes are unequal. Biometrika, 58(3), 545-554.

Rasch D, Masata O (2006). Methods of variance component estimation. Czech Journal of Animal Science, 51(6), 227.

Raudenbush SW, Bryk AS (1986). A hierarchical model for studying school. Sociology of Education, 59(1), 1-17.

Robinson DL (1987). Estimation and use of variance components. Journal of the Royal Statistical Society: Series D (The Statistician), 36(1), 3-14.

SAS Institute. SAS version 9.4 In. Cary, NC: SAS Institute; (2013).

Searle SR, Casella G, McCulloch CE (2006). Variance Components. Hoboken. John Wiley \& Sons, Inc. p. 1-501

Swallow WH, Monahan JF (1984). Monte Carlo comparison of ANOVA, MIVQUE, REML, and ML estimators of variance components. Technometrics, 26(1), 47-57.

Theobald CM, FIrat MZ, Thompson R (1997). Gibbs sampling, adaptive rejection sampling and robustness to prior specification for a mixed linear model [Bayesian inference, sire model]. Genetics Selection Evolution, 29(1), 57.

Wagenmakers EJ, Lee M, Lodewyckx T, Iverson GJ (2008). Bayesian versus frequentist inference. In Bayesian evaluation of informative hypotheses(pp. 181-207). Springer, New York, NY.

Zülkadir U, Şahin Ö, Aytekin İ, Boztepe S (2008). Malya kuzularda canlı ağırlık ve bazı vücut ölçülerinin tekrarlanma dereceleri. Selçuk Tarım Bilimleri Dergisi, 22(45), 89-93.

Zülkadir U, Aytekin İ (2009). Genetic analysis of test day milk yields of Brown Swiss cattle raised at Konuklar State Farm in Turkey using MTDFREML. South African Journal of Animal Science. 39(1):10-14. 